\title{
COMPARATIVE ANALYSES OF ENHANCING BANDWIDTH OF MICRO STRIP PATCH ANTENNAS: A SURVEY AND AN IDEA
}

\author{
Anilkumar Patil ${ }^{1}$, B.Suryakant ${ }^{2}$ \\ ${ }^{1}$ Asst Professor, SIT, Gulbarga \\ ${ }^{2}$ Professor, BKIT, Bhalki
}

\begin{abstract}
Microstrip Patch Antenna (MPA) is generally used in modern communication devices, and a large part of day-to-day communication is done through it. Study of literature of past few year shows that, the leading work on MPA is focused on designing compact sized broadband microstrip antenna. But inherently MPA have narrow bandwidth so to enhance bandwidth various techniques are engaged. This review paper demonstrates some commonly engaged techniques to fabricate MPA with broader-bandwidth since last few decades.
\end{abstract}

\section{INTRODUCTION}

Micro strip Patch Antenna (MPA) is commonly used because of its low profile, low cost and ease of manufacturing. A patch antenna is made by etching metal on one side of dielectric substrate where as on the opposite side there is continuous metal layer of the substrate which forms a ground plane [1]. MPAs a $\mathrm{r}$ e inherently a narrow band antennas so; various bandwidth enhancement techniques are engaged while keeping its size as compact as possible to be perfectly used as a low profile antenna.

Due to which many studies and researches are being done throughout the globe. Practically bandwidth of MPA is narrow but, today wireless communication systems require higher operating bandwidth. Such as about $7.6 \%$ for a global system for mobile communication (GSM; 890-960 MHz), 9.5\% for a digital communication system (DCS; 1710-1880 MHz), 7.5\% for a personal communication system (PCS; 1850-1990 M H z ), a n d $12.2 \%$ f o r a universal mobile telecommunication system (UMTS; 1920-2170 MHz) [2] To achieve these required bandwidths many techniques are used and some of them are given explained further in review this paper.

\section{BANDWIDTH-ENANCWMENT TECHNIQUES USED FOR MICROSTRIP PATCH ANTENNAS}

The major need for today's communication devices is to operate at broader band such as to support high speed internet, multimedia communication and similarly many more broadband services, this is achieved by using microstrip patch antennas, but inherently microstrip antennas are narrow band antennas so, various techniques are used to enhance the bandwidth of microstrip antenna.

In this section bandwidth enhancement or broadband techniques are explained Modified shape patch, Planar Multiresonator configuration, multilayered configuration and Stacked Multi-resonator microstrip patch antenna are mainly used for broadband microstrip antenna.

\subsection{Modified Shape Patch Broadband Microstrip Patch Antenna}

In this technique bandwidth enhancement is done by changing/modifying the shape of radiating patch. It is found that some shapes of patches have lower Q factor as compared to other therefore having high bandwidth [5]. These patches shapes include annular ring, rectangular/square ring, shorted patch and other geometries. There are several designs of broadband microstrip patch antenna with modified patches. A design of broadband circular patch microstrip antenna with Diamond shape slot is given by Garima, et al. [6].

This antenna is applicable for C-band. Substrate used in this antenna is FR-4 and produces the bandwidth of $13.58 \%$ when compared with conventional circular patch antenna. The performance of proposed antenna is improved when compared with that of conventional circular patch antenna having identical radius. Another design for modified shape patch is Tslot Broadband Rectangular Patch Antenna [7]. A single layer single probe fed

\subsection{Planar Multiresonator Configuration of}

\section{Broadband Microstrip Patch Antenna}

In such configuration of microstrip antenna multiple resonators are placed near to each other, only one is fed and others are parasitically coupled, it is also known as gap coupling. Another way used to feed multiresonator configuration is to directly connect the patches via microstrip 
line. In some cases hybrid coupling is also used which include gap and direct coupling [10]. Design of Bandwidth Enhancement of Microstrip Antennas Using Shifted Parasitically Coupled Planar Multiresonator [11]. In this method, a wideband planar multi resonator antenna with parasitic coupling is used. Results show gradual improvement in impedance bandwidth from $65 \mathrm{MHz}$ to $251 \mathrm{MHz}$ (about four times) with very minor variation of resonance frequency from $2.989 \mathrm{GHz}$ for reference patch to $3.023 \mathrm{GHz}$ for anticlockwise shifted parasitically coupled elements. In multiresonator broadband microstrip patch antenna [12], gap-coupled planar T-slot broad band rectangular patch antenna is proposed. Impedance bandwidth of $25.23 \%$ with an average gain of about $7.43 \mathrm{dBi}$ over the entire passband and peak gain of $9.88 \mathrm{dBi}$ at $-10 \mathrm{~dB}$ return loss is achieved. Single-layer single-patch wideband microstrip antenna with U- shaped slot Embedded on the patch [8]. Enhanced bandwidth is achieved by the U-shaped slot with a thick air substrate of $12 \mathrm{~mm}$ and the impedance bandwidth of $500 \mathrm{MHz}$ or $27.5 \%$ is achieved at the centre frequency $1815 \mathrm{MHz}$ (at $10 \mathrm{~dB}$ return loss). One more method of achieving broadband microstrip patch antenna is Modified E-H Shaped patch antenna [9].

A L-probe fed microstrip patch antenna with low crosspolarization and modified $\mathrm{E}-\mathrm{H}$ shaped patch design is proposed to operate at 1.79 to $2.34 \mathrm{GHz}$ frequency range. The impedance bandwidth achieved is $27 \%(550 \mathrm{MHz})$. All these techniques provide broadband microstrip patch antennas. In such configurations broader band is achieved without increasing the surface area of patch antenna multiresonator and stacked configurations are combined to obtain wide bandwidth with higher gain with three rectangular patches stacked on a single fed patch yielded bandwidth of $830 \mathrm{MHz}$ $(25.7 \%)$ with more than $10 \mathrm{~dB}$ gain. In multiresonator broadband microstrip antenna with directly coupled and parasitic patches [13]. The impedance bandwidth of $12.7 \%$ i.e. $365 \mathrm{MHz}$ at center frequency $2879 \mathrm{MHz}$ is obtained with 10 $\mathrm{dB}$ return loss. When one patch without any coupling (i.e. direct and parasitic coupling) is analyzed, impedance bandwidth of $54 \mathrm{MHz}$ (i.e. $2 \%$ ) is obtained at center frequency at $2710 \mathrm{MHz}$ 's When both cases are compared (i.e. $12 \% \mathrm{Vs}$ $2 \%$ ) then the impedance bandwidth of about6.35 times is obtained for proposed antenna.

Use of additional resonators patches either directly or gap coupled to the radiating patch will lead to abroad band configuration of microstrip antenna.

Though the size of resulting antenna is bigger but the resulting bandwidth is much more than that of a single patch microstrip antenna.

\subsection{Multilayered configurations of Broadband}

\section{Microstrip Patch Antenna}

In multilayered configuration patches are placed over different dielectric substrates and they are stacked on each other. Based on the coupling mechanism these configurations are of two types electromagnetically-coupled or dielectric constant. Main disadvantage of this multilayered microstrip configuration is its increased height which is not desirable in miniature devices and in aperature coupling ground plane which is having an aperture slot, and is made up of substrate with high dielectric constant to reduce radiation losses. Whereas the top patch is made up of thick substrate with lower aperture-coupled. Electromagnetic coupled microstrip antenna one or more patches are located on different dielectric layers. If two- layered configuration of broadband microstrip patch antenna is analyzed then any one of them may be fed and other is electromagnetically coupled.

Patch dimensions and dielectric constant of substrate may be different where as resonant frequency is closer to each other for obtaining broad bandwidth [14]. In aperture coupling, the field is coupled from the microstrip feed line placed on the other side of ground plane to the radiating patch through an electrically small aperture/slot in the ground plane. Two different dielectric substrates could be chosen one for the patch and other for feed line [14]. Very high bandwidth can be generated by using multilayered configurations. Near about $70 \%$ bandwidth can be generated using multilayered configuration.

Microstrip line feed electromagnetically coupled microstrip antenna [15] is a method of exciting the patch. This technique has the advantage that the dielectric constant of substrate used for microstrip feed line is high and it is thin so that radiation from feed line should be minimized, whereas the dielectric constant of substrate used for radiating patch is low and it is thick which improves the bandwidth of antenna [15]. Aperture coupled microstrip patch antenna is also an indirect technique of exciting patch. In this configuration feed line is on lower side of backward radiation is major problem [14].

\subsection{Stacked Multiresonator microstrip patch antenna}

In this configuration multiresonator and stacked configurations are combined to provide broadband microstrip patch antenna. A design of dual-frequency broadband stacked microstrip antenna using a reactive loading and a fractalshaped radiating edge [16], is used to obtain dual- frequency operation antenna is loaded with stub for changing frequency and which broader bandwidth is achieved by using stacked parasitic technique.

The central frequencies of the first and second operating bands are 1.524 and $2.159 \mathrm{GHz}$, bandwidth enhancement factor achieved is 22.3 in the first band and 18.7 in the second band and bandwidth achieved is $12 \%$ and 5\% respectively [16]. Another broadband design using stacked multiresonator configuration is gap-coupled planar multi-resonator and stacked configurations [12]; which is used to obtain wide 
bandwidth with higher gain with three rectangular patches stacked on a single fed patch yielded bandwidth of $830 \mathrm{MHz}$ $(25.7 \%)$ with more than $10 \mathrm{~dB}$ gain. A proposed broadband design using stacked U- slot microstrip antenna incorporating
E-shape and modified half-E shape radiating patches [17] are introduced. Maximum impedance bandwidth achieved is $60.2 \%$. It's though size of stacked multiresonator microstrip patch antenna is more but it yields high bandwidth.

\subsection{Tables for the Comparative Analyses of Broadband Techniques}

\begin{tabular}{|c|c|c|c|}
\hline $\begin{array}{l}\text { S. } \\
\text { No. }\end{array}$ & Broadband Techniques & Configurations & Remarks \\
\hline \multirow{4}{*}{1.} & \multirow{4}{*}{ Modified Shape Patch } & Diamond shape slot patch[6] & $\begin{array}{l}\text { Bandwidth achieved is } 13.58 \% \text { when } \\
\text { compared }\end{array}$ \\
\hline & & T-slot rectangular patch[7] & $\begin{array}{l}\text { Impedance Bandwidth of } 25.23 \% \text { with } \\
\text { average gain of } 7.43 \mathrm{dBi} \text { is obtained. }\end{array}$ \\
\hline & & $\begin{array}{l}\text { U-shaped slot with single-layer } \\
\text { single- patch }[8]\end{array}$ & $\begin{array}{l}\text { Air substrate of } 12 \mathrm{~mm} \text { is used to } \\
\text { yield bandwidth of } 27.5 \% \text {. }\end{array}$ \\
\hline & & E-H shaped patch[9] & Yielded bandwidth is about $27 \%$. \\
\hline \multirow{3}{*}{2.} & \multirow{3}{*}{ Multiresonator Technique } & $\begin{array}{l}\text { Shifted parasitically } \\
\text { coupled } \\
\text { multiresonator[11] }\end{array}$ & $\begin{array}{l}\text { Improves the impedance bandwidth from } \\
65 \\
\mathrm{MHz} \text { to } 251 \mathrm{MHz} \text { (about four times) with } \\
\text { minor variation of resonance frequency } \\
\text { from } 2.989\end{array}$ \\
\hline & & $\begin{array}{l}\text { Gap-coupled multiresonator and } \\
\text { stacked configuration[12] }\end{array}$ & $\begin{array}{l}\text { Yielded bandwidth of } 25.7 \% \text { with more } \\
\text { than } 10 \mathrm{~dB} \text { gain. }\end{array}$ \\
\hline & & $\begin{array}{l}\text { Directly coupled and } \\
\text { parasitic patches[13] }\end{array}$ & $\begin{array}{c}\text { Impedance bandwidth of } 12.7 \% \text { (365 } \\
\mathrm{MHz}) \text { is obtained, which is } 6.35 \text { times } \\
\text { when compared with the simple patch i.e. } \\
2 \%(54 \mathrm{MHz}) \text { at same center frequency of } \\
2879 \mathrm{MHz}\end{array}$ \\
\hline 3. & Multilayered Technique & $\begin{array}{l}\text { Multilayered configuration } \\
\text { of patches }[15]\end{array}$ & $\begin{array}{l}\text { Nearly } 70 \% \text { of bandwidth can be } \\
\text { generated by using multilayered } \\
\text { configuration of radiating patches. }\end{array}$ \\
\hline \multirow{3}{*}{4.} & \multirow{3}{*}{$\begin{array}{l}\text { Stacked Multilayered } \\
\text { Technique }\end{array}$} & $\begin{array}{l}\text { Dual-frequency stacked patch } \\
\text { with reactive loading[16] }\end{array}$ & $\begin{array}{l}\text { Bandwidth enhancement factor is } 22.3 \\
\text { and } 18.7 \text { for } 1.524 \mathrm{GHz} \text { and } 2.159 \mathrm{GHz} \\
\text { resp. which is further } 12 \% \text { and } 5 \% \text { for } \\
\text { their respective bands. }\end{array}$ \\
\hline & & $\begin{array}{l}\text { Gap-coupled planar multiresonator } \\
\text { and stacked configuration[12] }\end{array}$ & $\begin{array}{c}\text { Yielded bandwidth of } 25.7 \% \text { with more } \\
\text { than } 10 \mathrm{~dB} \text { gain }\end{array}$ \\
\hline & & $\begin{array}{c}\text { Stacked U-slot microstrip } \\
\text { antenna incorporating E-shape } \\
\text { and modified half-E shape } \\
\text { radiating patch }\end{array}$ & $\begin{array}{l}\text { Maximum impedance bandwidth of } \\
60.2 \% \text { can be obtained. }\end{array}$ \\
\hline
\end{tabular}




\subsection{Bandwidth Analysis by Introducing Slots in} Microstrip Antenna Design Using ANN.

In this method slotted MSA is designed on a substrate of thickness $1.588 \mathrm{~mm}$ that gives wideband characteristics using Artificial Neural Network (ANN). The patch antenna gives enhanced bandwidth as compared to antenna-without slots of the same physical dimensions. The bandwidth for the antenna is around $450 \mathrm{MHz}$ The present work signifies that by introduction of two slots in the same design, the bandwidth gets enhanced about $25 \%-45 \%$, i.e., from 450 to $650 \mathrm{MHz}$

\subsection{Enhancing the Bandwidth of a Microstrip Patch}

\section{Antenna using Slots Shaped Patch.}

In this method, three different geometry shapes, the $\mathrm{U}, \mathrm{E}$ and $\mathrm{H}$ are developed from a rectangular patch [20] shows that, bandwidth of conventional rectangular microstrip antenna can be enhanced from $4.81 \%$ (100MHz) to $28.71 \%(610 \mathrm{MHz}), 28.89 \%$ $(630 \mathrm{MHz})$ and $9.13 \%(110 \mathrm{MHz})$ respectively using $\mathrm{U}, \mathrm{E}$ and $\mathrm{H}-$ patch over the substrate. The E-shaped patch antenna has the highest bandwidth followed by U-shaped patch antenna and $\mathrm{H}$ shaped patch antenna.

\subsection{Comparative Study of Different Feeding} Techniques to Enhance Bandwidth of Microstrip Patch

\section{Antenna}

This paper describes variety of feeding technique applicable to microstrip patch antenna which is one of the important aspects. A good impedance matching condition between the line and patch without any additional matching elements depends heavily on feeding techniques used. The Coaxial Probe Feed Microstrip antenna provides a bandwidth of around $20 \%$. The bandwidth has been enhanced by using different feeding techniques are as fallows.

\begin{tabular}{|c|c|c|c|c|}
\hline S.no & Parameters & $\begin{array}{c}\text { Coaxial } \\
\text { probe } \\
\text { feed }\end{array}$ & $\begin{array}{c}\text { Aperture } \\
\text { Coupled } \\
\text { Feed }\end{array}$ & $\begin{array}{c}\text { L-band } \\
\text { Capacitivey } \\
\text { Coupled } \\
\text { Feed }\end{array}$ \\
\hline 01 & $\begin{array}{c}\text { Frequency } \\
(\mathrm{GHz})\end{array}$ & 5.35 & 2.25 & 1.25 \\
\hline 02 & Gain(dB) & 6.8 & 6 & 8 \\
\hline 03 & $\begin{array}{c}\text { Return } \\
\text { Loss(dB) }\end{array}$ & -14 & -14 & -42 \\
\hline 04 & $\begin{array}{c}\text { Bandwidth } \\
(\mathrm{MHz})\end{array}$ & 51 & $5 \%$ & 246 \\
\hline
\end{tabular}

\section{CONCLUSIONS}

After an extensive literature survey, it has been found that the bandwidth enhancement is an important area of study and research in microwave communication. Several techniques which are reported from time to time by many researches for enhancing the bandwidth of an MPA have been revised in this paper. Principles used, advantages and disadvantages of each method have been described out of all the techniques specified in this paper, multilayered technique and stacked multilayered techniques provide maximum bandwidth. The main intension of this study is to provide a useful reference to the researchers, designers and manufacturers of MPA.

\section{REFERENCES}

[1].Wikipedia,"http://en.wikipedia.org/wiki/Microstripanten na Dated: 05/11/2012 at 12:12AM

[2]. Kin-Lu Wong, "Compact and Broadband Microstrip Antennas", John Wiley \& Sons, page number: 12-14, ISBNs: 0-471-41717-3, 2002.

[3]. Kin-Lu Wong, "Compact and Broadband Microstrip Antennas", Copyright (C) John Wiley \& Sons, page number: 232-273, ISBNs: 0-471-41717-3, 2002.

[4]. David Sanchez-Hernandez and Ian D.Robertson, "A Survey of Broadband Microstrip Patch Antennas", Microwave Journal, page number: 1-10, Sept.1996.

[5]. Ramesh Garg, Parkash Bhartia, Inder Bahl and Apisak Ittipiboon, "Microstrip antenna design handbook", Artech House Antenna and Propagation Library, page number: 538, ISBN 0-89006-513-6, 2001.

[6]. Garima, D. Bhatnagar, J.S. Saini, V.K. Saxena and L.M. Joshi, "Design of broadband circular patch microstrip antenna with Diamond shape slot", Indian Journal of Radio and Space Physics Vol. 40, page number: 275-281, Oct. 2011.

[7]. Lolit Kumar Singh, Bhaskar Gupta and Partha P. Sarkar, "T-slot Broadband Rectangular Patch Antenna", International Journal of Electronic and Electrical Engineering Vol. 4, page number: 43-47, ISSN 0974-2174, 2011.

[8]. T. Huynh and K. F. Lee, "Single-layer single-patch wideband microstrip antenna", Electron. Lett. 31, page number: 1310-1311, Aug. 3, 1995.

[9]. Mohammad Tariqul Islam, Mohammed Nazmus Shakib and et al., "Modified E-H Shaped Microstrip Antenna for wireless Systems", IEEE International Conference on Networking, Proceedings, ISBN 978-1-4244-3492-3, page number: 794-796, Japan, March 26-29, 2009.

[10]. Girish Kumar and K.P. Ray, "Broadband microstrip antennas", Artech House antennas and propagation library, page number: 14, 89-90, ISBN 1-58053-244-6, 2003.

[11]. K. Chattopadhyay, S.K. Parui, S. Das and S.R. Bhadra Chaudhuri, "Bandwidth Enhancement of Microstrip Antennas Using Shifted Parasitically Coupled Planar Multiresonators", Applied Electromagnetics Conference 
(AEMC), IEEE, ISBN 978-1-4244-4819-7, 2009.

[12]. Girish Kumar and K.P. Ray, "Stacked gap-coupled multiresonator rectangular microstrip antennas", Antennas and Propagation Society International Symposium, IEEE Vol. 3, ISBN 0-7803-7070-8, page number: 514 - 517, Aug. 7, 2002.

[13]. C. K. Wu and K. L. Wong, "Broadband microstrip antenna with directly coupled and gap-coupled parasitic patches", Microwave Opt. Technol. Lett. 22, 348-349, Sept. 5, 1999.

[14]. Girish Kumar and K.P. Ray, "Broadband microstrip antennas", Artech House antennas and propagation library, page number: 15-17, ISBN 1-58053-244-6, 2003.

[15]. Girish Kumar and K.P. Ray, "Broadband microstrip antennas", Artech House antennas and propagation library, page number: 132-138, ISBN 1-58053-244-6, 2003.

[16]. J. Anguera, C. Puente and et al., "Dual-Frequency Broadband-Stacked Microstrip Antenna Using a Reactive Loading and a Fractal-Shaped Radiating Edge”, IEEE Antenna and Wireless Propagation Letter, VOL. 6, page number: 309312, ISSN 1536-1225, 2007.

[17]. M. A. Matin, B. S. Sharif and C. C. Tsimenidis, "Broadband Stacked Microstrip Antennas with Different Radiating Patch", Springer Science Business Media- Wireless Pers Commun, page number: 637-648, 11277-009-9836-7, Oct. 9, 2009.

[18]. V. V. Thakare, P. K. Singhal "Bandwidth Analysis by Introducing Slots In Microstrip antenna design using ANN". Progress In Electromagnetics Research M, Vol. 9, 107\{122\}, 2009.

[19]. Gagandeep Kaur Geetanjali Singla Simranjit Kaur "Design of Wideband Micro strip Patch Antenna Using Defected Ground Structure for Wireless Applications" (C) 2013, Volume 3, Issue 10, October 2013 ISSN: 2277 128X IJARCSSE

[20]. Atser A. Roy, Joseph M. Mom, Gabriel A. Igwue "Enhancing the Bandwidth of a Microstrip Patch Antenna using Slots Shaped Patch"AJER e-ISSN: 2320-0847 p- ISSN: 23200936 Volume-02, Issue-09, pp-23-30. 